\title{
IMMOBILIZATION AGENTS STUDY OF TOXIC ELEMENTS IN COAL ASH
}

\author{
JULIANA IZIDORO, DENISE FUNGARO, FELIPE CAMPELLO \& SABINE GUILHEN \\ Chemical and Environmental Technology Center, Nuclear and Energy Research Institute, Brazil
}

\begin{abstract}
Metal leaching from coal fly ashes into the environment is of a much concern. A series of batch tests were performed to investigate the potential leaching of metals from fly ash modified with organosilane (OS) and quaternary ammonium surfactant (SF). The fly ash was collected at the Figueira Thermal Power Plant, located in the city of Figueira, State of Paraná. Firstly, the influence of ash mass/water volume ratio on the concentration of the elements in the leachates from untreated fly ash was evaluated. Subsequently, the capacities of immobilization of toxic elements by the different immobilizing agents were determined by measuring the $\mathrm{pH}$ and conductivity of the leachates from the treated fly ash. A significant reduction in the concentration of the elements was observed for all the leachate samples obtained from the ashes treated with OS. The concentrations were reduced by $89 \%, 77 \%, 42 \%$ and $11 \%$ for $\mathrm{Cr}$, Mo, As and Se, respectively. When SF was used for the ash treatment, the concentration reduction in the leachates was found to be above $60 \%$ for all elements. These results show that both the OS and SF can be used as immobilizing agents for the retention of toxic elements presented in coal ashes.
\end{abstract}

Keywords: coal ashes, metal immobilizing agents, organosilane, surfactant.

\section{INTRODUCTION}

Industrial activities, whether in the transformation of raw materials for the production of consumer goods or obtaining industrial products, generate a large amount of solid waste and wastewater that need to be recycled, treated or discharged in a way to avoid damage to the environment.

The most viable method from both environmental and economic points of view is the reuse of these wastes in other industrial processes, making the manufacturing industry more sustainable as a whole. However, many by-products do not find an applicable use for other industrial processing, and often have low consumption in some markets. In this context, the energy generation plants, particularly coal-fired power plants, are parts of the industrial activities to produce a large amount of waste, coal combustion products (CCPs) or coal ashes, which are not completely reused in other processes. The surplus products of coal combustion are thus disposed in different ways, such as ash landfills, abandoned mines, sedimentation ponds, settling basins, etc. [1]-[3].

In Brazil, coal ash wastes are dumped in order to minimize their disposal and monitoring costs [4], which may, somehow, not avoid contamination on sites where they are deposited. In addition, storage of coal ashes in sedimentation ponds occupies large land areas, which could be used for other purposes, such as agriculture. Moreover, this type of disposal can generate various and serious environmental problems in the future. Therefore, studies of leaching and stabilization of coal combustion by-products are necessary in order to avoid the contamination in soil, surface water, groundwater and vegetation. It is well-known that the residue has high levels of trace dangerous elements such as $\mathrm{As}, \mathrm{Cr}, \mathrm{Mo}, \mathrm{Ni}, \mathrm{Se}$, and others [3], [5]. Those elements tend to concentrate mainly on the fly ashes in a smaller particle size [6].

Some immobilizing agents have been used to prevent the leaching of the toxic elements in coal ash, for example, surfactants, iron sulfate and iron chloride III [3], [7], [8]. 
In addition, Daniels et al. [9] reported that inorganic compounds, organic substrates (such as synthetic polymers), biochemical compounds (as biofilms) can also be used to immobilize trace elements from ashes. Recent studies have shown that silicon-containing organic compounds, organosilanes, can be mixed with coal ash to form a nanocomposite with hydrophobic surface, which can reduce the hydraulic conductivity of the ash and thus, alleviate the leaching capacity of toxic elements [9], [10]. Surfactants, similarly, can also modify the surface of the ashes, making it as a hydrophobic material to prevent the contact of its surface with the aqueous medium [11], [12].

Thus, the aim of the present work was to study the immobilization of the main toxic elements presented in coal fly ash by treatment ashes with immobilizing agents to reduce the possibility of environmental impacts of coal ash disposal.

\section{MATERIALS AND METHODS}

\subsection{Materials}

All the reagents used for the studies were of analytical grade. A coal fly ash from baghouse filter (CBF) was collected at the Figueira coal-fired power plant located in Paraná State, Brazil. Details of the characterizations of the CBF have been given in the previous papers [13], [14].

The quaternary ammonium salt, hexadecyltrimethylammonium bromide (HDTMA-Br, $\mathrm{CH}_{3}\left(\mathrm{CH}_{2}\right)_{15} \mathrm{~N}^{+}\left(\mathrm{CH}_{3}\right)_{3} \mathrm{Br} ; \quad$ M.W. $\left.=364,45 \mathrm{~g} \mathrm{~mol}^{-1}\right)$, and the organosilane ethoxytrimethylsilane (ETMS, $\mathrm{C}_{5} \mathrm{H}_{14} \mathrm{OSi}$; M.W. $=118,25 \mathrm{~g} \mathrm{~mol}^{-1}$ ) from Merck were used for ash modification.

\subsection{Preparation of modified fly ash}

Stock solutions of ETMS $\left(6.4 \mathrm{~mol} \mathrm{~L}^{-1}\right)$ and HDTMA-Br $\left(0.9 \mathrm{~mol} \mathrm{~L}^{-1}\right)$ were prepared and were diluted in the ratios of 1:10, 1:100 and 1: $1000(\mathrm{v} / \mathrm{v})$. The diluted samples were mixed with fly ash at a ratio of $5 \mathrm{~g}$ of fly ash to $10 \mathrm{~mL}$ of ETMS or HDTMA-Br solutions. The suspensions were vigorously mixed until pasty-like solutions were obtained and then were allowed to dry at room temperature. The samples of the modified fly ash with ETMS and HDTMA-Br are listed in Tables 1 and 2, respectively.

Table 1: Samples of organosilane-modified fly.

\begin{tabular}{|c|c|}
\hline Sample & ETMS: water ratio (v/v) \\
\hline OMF-1 & $1: 10$ \\
\hline OMF-2 & $1: 100$ \\
\hline OMF-3 & $1: 1000$ \\
\hline
\end{tabular}

Table 2: Samples of surfactant-modified fly ash.

\begin{tabular}{|c|c|}
\hline Sample & HDTMA-Br: water ratio (v/v) \\
\hline SMF-1 & $1: 10$ \\
\hline SMF-2 & $1: 100$ \\
\hline SMF-3 & $1: 1000$ \\
\hline
\end{tabular}


Table 3: Samples of untreated fly ash.

\begin{tabular}{|c|c|}
\hline Sample & Liquid-to-solid ratio (mL:g) \\
\hline UFA-1 & $10: 1$ \\
\hline UFA-2 & $20: 1$ \\
\hline UFA-3 & $30: 1$ \\
\hline UFA-4 & $40: 1$ \\
\hline UFA-5 & $50: 1$ \\
\hline
\end{tabular}

\subsection{Leaching tests}

\subsubsection{Leaching tests with untreated fly ash}

The methodology of the leaching test was described previously in a reference [10]. A mass of $2.5 \mathrm{~g}$ of untreated fly ash (UFA) was mixed with deionized water in different proportions, as shown in Table 3. The samples were shaken manually and were allowed to stand for $24 \mathrm{~h}$. After that, the slurries were filtered with a Nalgon filter paper ( 0.45 micrometer).

The $\mathrm{pH}$ and conductivity of the leachates were determined immediately after the collection using a pH probe (Orion Model 91560) and a conductance meter (YSI Model 35), respectively. The remaining solutions were then analyzed by inductively coupled plasma optical emission (ICP-OES - Spectro, Modelo Arcos).

\subsubsection{Leaching tests with treated fly ash}

A mass of $2.5 \mathrm{~g}$ of treated fly ash samples (Tables 1 and 2) was mixed with deionized water. The water: fly ash $(\mathrm{L} / \mathrm{S})$ ratio was defined in the leaching test described above in section 2.3.1. The samples were shaken manually and were allowed to stand for $24 \mathrm{~h}$. After filtration, the leachates were analyzed as previously described.

\section{RESULTS AND DISCUSSION}

\subsection{Influence of volume water/mass fly ash ratio on the metal leaching}

The batch leaching test for coal fly samples was designed to simulate leaching under rain or other water washing. The ratio of the volume of leaching solution to the mass of fly ash $(\mathrm{L} / \mathrm{S})$ is one of the important factors affecting the leaching extent of trace elements from the ashes. A lower $\mathrm{L} / \mathrm{S}$ ratio represents restricted throughput, while increasing the $\mathrm{L} / \mathrm{S}$ ratio indicates higher throughput of water through the ash as expected in an open disposal pond. Tab. 4 shows the concentrations of some elements in the leaching behavior from the original fly ash. The metals analyzed include $\mathrm{Al}, \mathrm{Cr}, \mathrm{Zn}, \mathrm{Mo}, \mathrm{As}, \mathrm{Cd}, \mathrm{Pb}$ and Se and were selected due to their high levels in coal fly ash samples of Figueira coal-fired power plant according to previous studies [5], [15].

It is observed that $\mathrm{Cd}$ and $\mathrm{Pb}$ practically did not leach from the ash regardless of $\mathrm{L} / \mathrm{S}$ ratio as their concentrations were below the detection limits in most of the leachates at all L/S ratios. In general, the concentrations of the elements in leachates gradually decreased at higher L/S ratios, except $\mathrm{Zn}$ without any trend. The decreasing concentration of an element with increasing $\mathrm{L} / \mathrm{S}$ ratio indicates that, with time, the concentration of that particular element in the leachate would reduce [16]. 
Table 4: Samples of untreated fly ash.

\begin{tabular}{|c|c|c|c|c|c|}
\hline \multirow{2}{*}{ Element } & \multicolumn{5}{|c|}{$\begin{array}{c}\text { Concentration } \\
\left(\mathrm{mg} \mathrm{L}^{-1}\right)\end{array}$} \\
\cline { 2 - 6 } & UFA-1 & UFA-2 & UFA-3 & UFA-4 & UFA-5 \\
\hline $\mathrm{Cr}$ & 0.235 & 0.127 & 0.107 & 0.084 & 0.073 \\
\hline $\mathrm{Zn}$ & 0.0237 & 0.0147 & 0.0106 & 0.0315 & 0.072 \\
\hline $\mathrm{Mo}$ & 1.16 & 0.583 & 0.45 & 0.03412 & 0.287 \\
\hline $\mathrm{As}$ & 1.53 & 1.40 & 1.2 & 1.30 & 1.35 \\
\hline $\mathrm{Cd}$ & $<0.0013$ & $<0.0013$ & $<0.0013$ & $<0.0013$ & $<0.0013$ \\
\hline $\mathrm{Pb}$ & $<0.004$ & $<0.004$ & $<0.004$ & 0.0072 & 0.031 \\
\hline $\mathrm{Se}$ & 0.068 & 0.034 & 0.032 & 0.025 & 0.025 \\
\hline
\end{tabular}

The high leachability of elements is related to the fractions of water soluble and/or exchangeable compounds. The relatively lower leachability could be related to the significant amount of the element associated with moderately reducible amorphous iron/aluminum oxides and with crystalline Fe oxides or bound to organics/sulfides [3].

According to Table 4, arsenic, molybdenum, chromium and selenium presented higher concentrations in the leachate at 10:1 L/S. Taking into account the value of leaching degree of each element, it can be concluded that the degree of leaching is decreasing in the following order: $\mathrm{As}>\mathrm{Mo}>\mathrm{Cr}>\mathrm{Se}$.

In coal fly ash, As, Cr, Mo, and Se can be presented as surface enrichment, impurities in crystalline components, or as discrete accessory crystalline phases [17], [18]. Previous studies indicated that $\mathrm{As}, \mathrm{Cr}, \mathrm{Mo}$, and Se existed as oxyanions in all fly ash leachate solutions [19]. Therefore, in this study, these elements (As, Cr, Mo, and Se) were selected as the target elements in the leaching tests under an L/S ratio of 10:1 with modified fly ash due to human and environmental health concerns. In ASTM D3987 test, solid-to-liquid (L:S) ratio is generally applied between 3:1 and 10:1 [20].

\subsection{The effect of immobilizing agents}

The leaching tests for the treated fly ash with organosilane are shown in Table 5. The concentrations of the four elements in leachates were decreased after the treatment of fly ash with ethoxytrimethylsilane. However, there was no significant difference at the three dilutions.

Samples of organosilane-modified fly ash presented significant reductions in $\mathrm{Cr}$ and $\mathrm{Mo}$ elements (77-90\%), while for As and Se, the reductions (40-65\%) were less pronounced. The selenium concentration in OMF-2 sample is higher (12\% mobility reduction). The difference in leaching behavior of this sample can be attributed to the heterogeneity of the coal fly ash.

The concentrations of elements in the eluted solution from surfactant treated fly ash samples are presented in Table 6. The dosage of surfactant can affect the effectiveness of surface modification significantly [8]. 
Table 5: Trace elements leached from untreated fly ash and organosilane-modified fly ash samples.

\begin{tabular}{|c|c|c|c|c|}
\hline \multirow{2}{*}{ Element } & \multicolumn{4}{|c|}{$\left.\mathrm{C}_{(\mathrm{mg} \mathrm{L}}{ }^{-1}\right)$} \\
\cline { 2 - 5 } & $\begin{array}{c}\text { Fly ash without } \\
\text { treatment }\end{array}$ & OMF-1 & OMF-2 & OMF-3 \\
\hline $\mathrm{Cr}$ & $0.235 \pm 0.004$ & $0.020 \pm 0.001$ & $0.024 \pm 0.001$ & $0.034 \pm 0.001$ \\
\hline $\mathrm{Mo}$ & $1.16 \pm 0.01$ & $0.280 \pm 0.004$ & $0.265 \pm 0.004$ & $0.262 \pm 0.001$ \\
\hline $\mathrm{As}$ & $1.53 \pm 0.05$ & $0.890 \pm 0.01$ & $0.875 \pm 0.006$ & $0.757 \pm 0.003$ \\
\hline $\mathrm{Se}$ & $0.068 \pm 0.002$ & $0.035 \pm 0.002$ & $0.060 \pm 0.001$ & $0.024 \pm 0.001$ \\
\hline
\end{tabular}

Table 6: $\quad$ Trace element leached from untreated fly ash and surfactant-modified fly ash samples.

\begin{tabular}{|c|c|c|c|c|}
\hline \multirow{2}{*}{ Sample } & \multicolumn{4}{|c|}{ Elements } \\
\cline { 2 - 5 } & $\mathrm{Cr}$ & Mo & As & Se \\
\hline $\begin{array}{c}\text { Fly ash } \\
\text { without } \\
\text { treatment }\end{array}$ & $0.235 \pm 0.004$ & $1.16 \pm 0.01$ & $1.53 \pm 0.05$ & $0.068 \pm 0.002$ \\
\hline SMF-1 & $0.020 \pm 0.0009$ & $0.990 \pm 0.07$ & $0.282 \pm 0.01$ & $0.0132 \pm 0.002$ \\
\hline SMF-2 & $0.0267 \pm 0.001$ & $1.014 \pm 0.07$ & $0.445 \pm 0.07$ & $0.0161 \pm 0.003$ \\
\hline SMF-3 & $0.0186 \pm 0.005$ & $0.410 \pm 0.03$ & $0.448 \pm 0.03$ & $0.0162 \pm 0.003$ \\
\hline
\end{tabular}

According to adsorption of ionic surfactants onto solid surface, various forms of the surfactant aggregate: monolayers, bilayers, or variations between the two forms, are presented, depending on the surfactant concentration. Therefore, there is a difference of surfactant molecular configuration as well as the fractional organic carbon content [21], [22] on ash samples.

In addition, the surfactant concentration also influences the hydrophobicity of the material. The highest hydrophobicity degrees are achieved at higher dosages of surfactant up to the optimum value. Beyond that, further increase in surfactant dosages resulted in the decrease in hydrophobicity [8], [23]. This effect can be due to multi-layer adsorption of the surfactant causing sticking of particles on the surface of fly ash, or a change in surfactant orientation to expose hydrophilic head groups, causing a charge reversal on the surface [24]. 
According Table 6 , all the treatment showed $\sim 90 \%$ reduction of $\mathrm{Cr}$ leaching. The treatments also reduced the mobility of Mo from all the fly ash samples by $13-79 \%$ reduction and showed a significant reduction in As and Se from the fly ash (60-80\%). In general, the mobility reduction of trace elements after treatment of the ash with SF followed the descending order: $\mathrm{Cr}>\mathrm{Se}>\mathrm{As}>\mathrm{Mo}$. The order observed with organosilane-modified fly ash samples was $\mathrm{Cr}>\mathrm{Mo}>\mathrm{Se}>\mathrm{As}$. A study reported a $100 \%$ decrease in the leachability of $\mathrm{Cr}$ in organosilane-treated fly ash but less effective for As, B and Se [9].

\subsection{Mechanism of adsorption of immobiling agents on coal ash}

Fly ash is mainly composed of silicon dioxide, aluminium oxide and iron (III) oxide, which are polar compounds, making the fly ash hydrophilic. One common means of imparting hydrophobic properties to surfaces is the process known as silylation of fly ash surface with organosilane or use of surface-active agents [9], [11], [12] will make the surface hydrophobic.

Previous studies have suggested that the main benefit of organosilane modification is derived from the covalent bonding between the organic modifier and the siliceous substrates present on the surface of the fly ash [9], [25]. The process of surface modification of fly ash with organosilane is shown in Fig. 1.

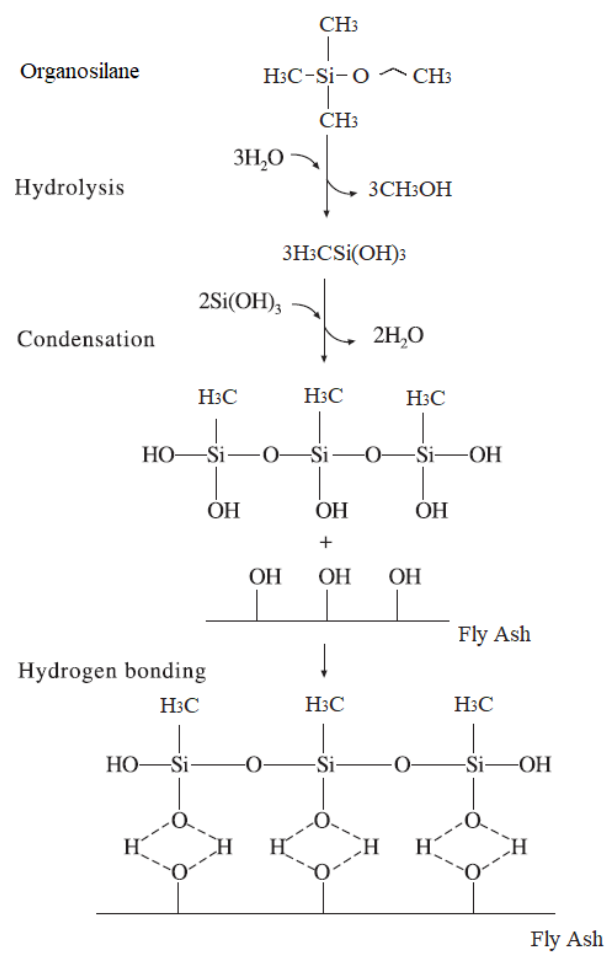

Figure 1: Schematic illustration of the hydrolytic deposition of the organosilane. ethoxytrimethylsilan on the fly ash surface. (Source: adapted from Hydrophobicity, hydrophilicity, and silane surface modification, 2017.) 
Table 7: $\mathrm{pH}$ and electrical conductivity values in fly ash leachates samples.

\begin{tabular}{|c|c|c|}
\hline Samples & $\mathrm{pH}$ & Conductivity $(\mu \mathrm{S} / \mathrm{cm})$ \\
\hline Fly ash without treatment & $9.03 \pm 0.11$ & $441.97 \pm 3.28$ \\
\hline CNT & $8.45 \pm 0.002$ & $455.32 \pm 2.51$ \\
\hline OMF-1 & $8.00 \pm 0.02$ & $480.22 \pm 1.89$ \\
\hline OMF-2 & $8.22 \pm 0.06$ & $421.47 \pm 3.42$ \\
\hline OMF-3 & $7.10 \pm 0.01$ & $355.02 \pm 3.48$ \\
\hline SMF-1 & $7.27 \pm 0.03$ & $331.43 \pm 1.74$ \\
\hline SMF-2 & $7.58 \pm 0.02$ & $327.00 \pm 3.50$ \\
\hline SMF-3 & $7.41 \pm 0.001$ & $331.43 \pm 2.02$ \\
\hline
\end{tabular}

The reaction scheme for the surface modification of fly ash with a surfactant is shown in eqn (1). HDTMA-Br reacts readily with free hydroxyl groups on the fly ash surface to form a Si-O-N-C moiety [11], [12].

$$
\mathrm{Si}-\mathrm{OH}+\mathrm{Br}\left[\left(\mathrm{CH}_{3}\right)_{3} \mathrm{NC}_{16} \mathrm{H}_{33}\right] \rightarrow \mathrm{Si}-\mathrm{O}-\mathrm{N}\left[\left(\mathrm{CH}_{3}\right)_{3}\left(\mathrm{C}_{16} \mathrm{H}_{33}\right)\right]+\mathrm{HBr} \text {. }
$$

\subsection{Effect of different treatments on leachate $\mathrm{pH}$ and conductivity from fly ash samples}

The $\mathrm{pH}$ and conductivity values of the leached fly ash samples are shown in Table 7. The $\mathrm{pH}$ values of leachate from untreated fly ash and fly ash treated with organosilane were alkaline. This was due to the hydrolysis of metal oxides in fly ash [27], [28].

According to Table 7, the $\mathrm{pH}$ values of the ash treated with surfactants had a $\mathrm{pH}$ close to 7.0, a neutral character. This fact can be attributed to the formation of $\mathrm{HBr}$ when the substrate binds to the surface of the ash, according to eqn (1).

The conductivity values of the untreated ash and treated with organosilane were very close (Table 7). The conductivity values of the ash treated with HDTMA-Br were lower than the values obtained for the other samples showing that the surfactant is more efficient to prevent the release of ions in solution.

\section{CONCLUSION}

Batch leaching tests of a coal fly ash sample showed the presence of several environmentally available trace elements, mainly As, $\mathrm{Cr}$, Mo, and Se. Moreover, as was the most labile and Se was the least mobile of the oxyanion-forming trace elements. It was also found that some elements, like $\mathrm{Cd}$ and $\mathrm{Pb}$ were insignificant in the leachates. The elements showed the maximum concentrations in the leachate at low $\mathrm{L} / \mathrm{S}$ of 10 . The treatments with hexadecyltrimethylammonium bromide and ethoxytrimethylsilane were shown to be an effective method for the sequestration of the oxyanion presented in coal fly ash. In general, mobility reduction of the metals was in the range $50-90 \%$ for most treatments. 


\section{REFERENCES}

[1] Iyer, R.S. \& Scott, J.A., Power station fly ash - a review of value-added utilization outside of the construction industry. Resour. Conserv. Recy., 31, pp. 217-228, 2001.

[2] Rohde, G.M., Zwonok, O., Chies, F. \& Silva, N.I.W. (eds), Cinzas de carvão fóssil no Brasil - Aspectos técnicos e ambientais, Porto Alegre: CIENTEC. p. 202, 2006.

[3] Bhattacharyya, S., Investigation of natural weathering processes and artificial treatment techniques in the attenuation of toxic metals from coal fly ash, Department of Geological Sciences, The University of Alabama, p. 226, 2010.

[4] Universidade Federal Do Rio Grande Do Sul - UFRGS. Carvão e meio ambiente, Centro de Ecologia/UFRGS, Porto Alegre: Ed. Universidade/UFRGS, 2000.

[5] Depoi, F. S., Pozebon, D. \& Kalkreuth, W. D., Chemical characterization of feed coals and combustion-by-products from Brazilian power plants. Int. Journal coal geol., 76, pp. 227-236, 2008.

[6] Izidoro, J.C., Miranda, C., Ghilhen, S.N. \& Fungaro, D.A., Chemical, mineralogical and environmental characterization of combustion by-products generated from mineral coal used for electricity production. Proceedings of the 13th International Conference on Materials Chemistry - MC13, p. 46, 2017.

[7] Meng, X., Bang, S. \& Korfiatis, G.P., Effects of silicate, sulfate, and carbonate on arsenic removal by ferric chloride. Water Research, 34(4), pp. 1255-1261, 2000.

[8] Qian, G., Zhang, H., Zhang, X. \& Chui, P.C., Modification of MSW fly ash by anionic chelating surfactant. Journal of Hazardous Materials, B121, pp. 251-258, 2005.

[9] Daniels, J.L., Hourani, S.M. \& Harper, S.L., Organo-silane chemistry: A water repellent technology for coal ash and soils. Proceedings of the 2009 World of Coal Fly Ash (WOCA), pp. 1-9, 2009.

[10] Daniels, J.L. et al., Nano-scale organo-silane applications in geotechnical geoenvironmental engineering. International Journal of Terraspace Science and Engineering, 1(I), pp. 19-27, 2009.

[11] Banerjee, S.S., Joshi, M.V. \& Jayaram, R.V., Effect of quaternary ammonium cations on dye sorption to fly ash from aqueous media. J. Colloid Interface Sci., 303(2), pp. 477-483, 2006.

[12] Banerjee, S.S., Joshi, M.V. \& Jayaram, R.V., Treatment of oil spills using organo-fly ash. Desalination, 195, pp. 32-39, 2006.

[13] Izidoro, J.C., Fungaro, D.A., Santos, F.S. \& Wang, S., Characteristics of Brazilian coal fly ashes and their synthesized zeolites. Fuel Proc. Technol., 97, pp. 38-44, 2012.

[14] Fungaro, D.A., Izidoro, J.C., Santos, F.S. \& Wang, S., Coal fly ash from brazilian power plants: chemical and physical properties and leaching characteristics. In: Sarker, P.K. ed. Fly Ash: Chemical Composition, Sources and Potential Environmental Impacts, Hauppauge, Nova Science Publishers: New York, pp. 145-164, 2013.

[15] Lange, C.N., Contaminação do solo e mobilidade de As, Cd, Mo, Pb e Zn em colunas de solo franco arenoso com cinza de carvão, Instituto de Pesquisas Energéticas e Nucleares: São Paulo, p. 150, 2012.

[16] Praharaj, T., Powell, M.A., Hart, B.R. \& Tripathy, B.S., Leachability of elements from sub-bituminous coal fly ash from India. Environment International, 27, pp. 609-615, 2002.

[17] Linton, R.W., Loh, A., Natusch, D.F., Evans, J.R.C.A. \& Williams, P., Surface predominance of trace elements in airborne particles. Science, 191, pp. 852-854, 1976.

[18] Vassilev, S.V. \& Vassileva, C.G., Geochemistry of coals, coal ashes and combustion wastes from coal-fired power stations. Fuel Process Technol., 51, pp. 19-45, 1997. 
[19] Neupane, G. \& Donahoe, R.J., Leachability of elements in alkaline and acidic coal fly ash samples during batch and column leaching tests. Fuel, 104, pp. 758-770, 2013.

[20] Yilmaz, H., Characterization and comparison of leaching behaviors of fly ash samples from three different power plants in Turkey. Fuel Processing Technology, 137, pp. 240-249, 2015.

[21] Haggerly, G.M. \& Bowman, R.S., Sorption of chromate and other inorganic anions by organo-zeolite. Environ. Sci. Technol., 28, pp. 452-458, 1994.

[22] Li, Z. \& Bowman, R. S., Counterion effects on the sorption of cationic surfactant and chromate on natural clinoptilolite. Environ. Sci. Technol., 31, pp. 2407-2412, 1997.

[23] Taffarel, S.R. \& Rubio, J., Adsorption of sodium dodecyl benzene sulfonate from aqueous solution using a modified natural zeolite with CTAB. Minerals Engineering, 23, pp. 771-779, 2010.

[24] Sullivan, E.J., Hunter D.B. \& Bowman, R.S., Topological and thermal properties of surfactant-modified clinoptilolite studied by tapping-mode atomic force microscopy and high-resolution thermogravimetric analysis. Clays Clay Min., 45 pp. 42-53, 1997.

[25] Isnaeni, D., Kusumastuti, E. \& Sulistyaningsih, T., The effect of silane addition on chitosan-fly ash/CTAB as electrolyte membrane. Materials Science and Engineering, 6(2), pp. 125-132, 2017.

[26] Hydrophobicity, hydrophilicity, and silane surface modification; Galest Inc., Online. www.gelest.com/wp-content/uploads/Hydrophobicity.pdf. Accessed on: 21 Nov. 2017.

[27] Talbot, R.W., Anderson, M.A. \& Andren, A.W., Qualitative model of heterogeneous equilibriums in a fly ash pond. Environ. Sci. Technol., 12, pp. 1056-1062, 1978.

[28] Roy, W.R., Griffin, R.A., Illinois basin coal fly ashes. 2. Equilibria relationships and quantitative modelling of ash-water reactions. Environ. Sci. Technol., 18, pp. 739$742,1984$. 